\title{
Socio-demographic Predictors of Cancer Patients Caregiver Burden: A descriptive Cross-sectional Study of Central India
}

\section{Deepak Mittal' ${ }^{1}$, Shashi Prabha Tomar' ${ }^{2}$, Rajesh Tiwari ${ }^{3}$}

'Resident, Department of Community Medicine, NSCB Medical College, Jabalpur, lndia; 'Associate Professor, Department of Community Medicine, NSCB Medical College, Jabalpur, India; 3 Professor and Head, Department of Community Medicine, NSCB Medical College, Jabalpur, India.

\section{ABSTRACT}

Introduction: In India, around 2.0-2.5 million people are living with one or another kind of cancer menace and above 7-8 lakhs new cases added every year to the existing burden. Availability of data in this regard is mostly from developed countries where the social-demographic scenarios are quite different from developing countries on comparing data from developed countries. Although fewer studies had been carried out in India in this regard seems to be non-sufficient for addressing the problem.

Objective: To explore social-demographic predictors of Caregiver burden among caregivers of cancer patients attending cancer hospital Jabalpur.

Methods: This is a descriptive cross-sectional, hospital-based study conducted in cancer hospital Jabalpur in 340 caregivers. Chi-square test was applied to determine the association of study variables with caregiver burden. Results: Mean scores as assessed by ZBI was found to be $38 \pm 11$ (median = 36). $197(57.9 \%)$ caregivers were male, $143(42.1 \%)$ were female. $81 \%$ of males feel cared for giving burden, while among females only $55(41.4 \%)$ feel it. Despite contributing only $40.6 \%$ study population, urban caregivers experienced significantly high (82\%) caregiver burden. the maximum caregiving burden observed in middle class $86.4 \%$, which constitutes only $25 \%$ of the study population and the caregiver burden was found statistically significant.

Conclusion: These finding suggested coping with the problem of care-giving burden more policies and programmes in this direction should have been planned with special attention particularly to reduce burden amongst those having more suffering.

Key Words: Zarit burden Interview, Institutional ethics committee, Caregiver burden

\section{INTRODUCTION}

In India, around 2.0-2.5 million people are living with one or another kind of cancer menace and above 7-8 lakhs new cases added every year to the existing burden ${ }^{1}$. Quite often the need and demand of these caregivers are often overlooked and neglected during the provision of care and treatment, the entire focus remains on the patient itself. ${ }^{1}$ The vital role played by such caregivers is well recognized, but the burden on them is poorly understood. The caregiver burden outcome depends upon several variables. It has been noticed that among cancer patients assistance in activities of daily living and instrumental activities of daily living has a significant impact on caregiver burden..$^{2-4}$ It's very unfortunate that overall health or physical, psychosocial, and spiritual wellbeing of these caregivers compromised during provision of care to a seriously ill family member. ${ }^{4}$ In a recent metaanalysis, it was demonstrated that such caregivers had worse physical and mental health than their non-Care giving peers. ${ }^{5}$ Availability of data in this regard is mostly from developed countries where the social-demographic scenarios are quite different from developing countries On comparing data from developed countries. Although Fewer studies had been carried out in India in this regard seems to be non-sufficient for addressing the problem. ${ }^{6,7}$

Hence it is more than essential to explore social-demographic predictors of Caregiver burden among caregivers of cancer patients attending cancer hospital of Jabalpur MP: A descriptive cross-sectional study of central India.

\section{MATERIALS AND METHODS}

Settings and Design: The study was conducted in the Outpatient Department of Cancer Hospital, Jabalpur (M.P) hich

\section{Corresponding Author:}

Dr. Shashi Prabha Tomar, Associate Professor, Department of Community Medicine, NSCB Medical College, Jabalpur, India. Email: tomarshashi9@gmail.com

ISSN: 2231-2196 (Print)

Received: 19.07 .2020
ISSN: 0975-5241 (Online)

Revised: 21.09 .2020
Accepted: 02.11 .2020
Published: 14.12 .2020 
is a tertiary care hospital. Methodology- Study design: Descriptive Cross-sectional study Duration of study: April 2018 to March 2019.

Study subjects: 340 caregivers of cancer patients

Caregiver: In this study Caregiver is an unpaid person, in close relation to the patient, caring for a minimum of 15 days since diagnosis and awareness of the patient's disease and ongoing treatment.

\section{Inclusion criteria:}

1. Cancer patients accompanied by a caregiver.

2. A caregiver who is in close relation to a patient, caring for a minimum of 15 days and accompanied by the cancer patient on the day of the interview.

Exclusion criteria: A caregiver who did not give consent.

Sample size calculation: The estimated sample size was calculated according to the formula: on $=\mathrm{Z} 2 \mathrm{pq} / 12$

Where, $Z=$ confidence interval, $\mathrm{P}(\%)=$ prevalence of caregiver burden $\mathrm{Q}(\%)=100-\mathrm{p}(\%)$, and $\mathrm{L}=$ allowable error.

Caregiver burden prevalence varies from $28 \%$ to $67 \% .{ }^{9}, 10 \mathrm{By}$ taking prevalence (p) as $28 \%$, with the absolute error (l) as $5 \%$ And $\mathrm{Z}$ as 1.96 to $95 \%$ confidence interval, the sample size was calculated to be 309 . By adding $10 \%$ non-respondents, the final sample size came out to be 339 , which was rounded off to 340.340 caregivers accompanying cancer patients were included in the study. Sampling technique 340 caregivers accompanied the cancer patients who fulfilled the inclusion criteria of the study were included in the study.

\section{Study Tool and Data Collection Techniques}

The technique for data collection was face to face interviews and record reviews. A predesigned, semi-structured questionnaire was used to assess the socio-demographic profile and burden on caregivers of cancer patients. Study Variables such as Age, Gender, Religion, Area of residence, Level of education, socioeconomic status, type of family, and presence of comorbid physical illness included in study instrument.

\section{Statistical analysis}

Caregiving burden assessed by using a short burden scale Zarit burden scale (ZBI).

Scale for assessment of the burden on caregivers of cancer patients.

\section{Zarit burden Interview (ZBI)}

It is a standard, validated tool which was used to assess the burden on caregivers. A 5 point Likert scale using five main domains of burden, namely health, psychological well- being, finances, social life and relationship with the patient and
22 items has been used. A score of 0-4 represents a higher burden. The ZBI enables the measurement of caregiving burden with subscales of burden in the relationship (6 items), emotional well-being (7 items), social and family life (4 items), finances (1 item), and loss of control over one's life (4 items). The final scores range from 0 to 88 . It is further stratified into four categories. ${ }^{11}$

0-20 - no or minimal burden,

$>21$ - Burdened

Data obtained was coded and entered using Microsoft office excels 2007. Collected data were checked for its completeness and correctness before analysis. Data were finally tabulated and analyzed using statistical software called SPSS 20. Descriptive analyses were reported as means with standard deviation and proportions. A Chi-square test was applied to determine the association of socio-demographic variables with caregiver burden. Statistical significance was evaluated at a $5 \%$ level of significance. A p-value of less than 0.05 was found to be statistically significant.

\section{Ethical Consideration}

Ethical clearance was taken from the Institutional Ethics Committee. Permission was also obtained from the Department of Oncology, Cancer Hospital Jabalpur (MP). Written informed consent was obtained from all the participants who volunteered for the study. Oral consent was obtained from each patient after explaining the purpose of the study.

\section{RESULTS}

Among 340 caregivers interviewed Caregiver burden found $72.4 \%$ among caregivers of cancer patients. Mean scores as assessed by ZBI was found to be $38 \pm 11$ (median = 36). 197 $(57.9 \%)$ caregivers were male, $143(42.1 \%)$ were female. $81 \%$ of males feel cared for giving burden, while among females only 55 (41.4\%) feel it. Most of the study subjects were in the range of age 30-59 years, which consisted of two age groups 30-44 and 45-69 years, each having $43.5 \%$ caregivers. The mean age of the caregivers was observed to be $43.45 \pm 9.49$ years. The maximum caregiver burden was observed in 30 to 45 age group $82.4 \%$. Despite contributing only $40.6 \%$ study population, urban caregivers experienced significantly high $(82 \%)$ caregiver burden. As far marital status is concerned, unmarried caregivers were found to be more burdened $(77.3 \%)$ as compared to other marital statuses. Association of type of family and caregiver burden was also not found significant However association of marital status with caregiver burden was not found significant. The caregiver participants who had a co-morbid illness were found to be significantly more burdened $(80.9 \%)$ than those who had no co-morbid illness $(67.3 \%)$. 
The maximum number of caregivers had a joint family (59.4 $\%)$ and had a nuclear family (40.6\%). 40.6\% educated middle and above subjects(76. 8\%) caregiving burden was observed in contrast mere $14 \%$ illiterate study population experienced a $65 \%$ caregiving burden. Maximum numbers of the caregivers were housewives $(20.9 \%)$, followed by the farmer $(17 \%)$ and unskilled workers (16.5\%) least were professionals $(3.8 \%)$. Despite contributing the highest in numbers caregiving burden was felt least among housewives (69\%). While the contrast was seen among professional contributing least in numbers for caregiving had experienced a lot of Caregiving burden (61.5\%). Table 1B reveals, despite a majority of study subjects belong to lower and lower-middleclass $52.6 \%$, the maximum caregiving burden observed in middle class $86.4 \%$, which constitutes only $25 \%$ of the study population and the caregiver burden was found statistically significant.

\section{DISCUSSION}

In the present study male and the younger age group, 30 to 45 were found to be significantly burdened. This could be due to that age group 30-44 comprises young people who have started a new life and all responsibility for earning and rearing of children on them so burden in them may be found higher than others and by nature females are less hesitating to take care of others as compared to males so the burden in females may be found lower than males. Similar to the findings of this study, Lukhmana S, et al ${ }^{12}$ among 200 family caregivers of cancer patients reported that the mean age of the participant was found to be $40 \pm 11.3$ years. Similarly, Lixia and Mordiffi ${ }^{13}$ did a systematic review for identifying factors associated with higher caregiver burden among family caregivers of elderly cancer patients reported that younger caregivers and males had higher caregiver burden. Findings were in agreement with this study. In contrast Hiremath P, et al. ${ }^{14}$ reported that the education of caregivers was not significantly associated with caregiver burden as in present study education was not significantly associated with caregiving burden). However, the association of occupational status with caregiver burden was not found significant. Hiremath $\mathrm{P}$ et al. ${ }^{14}$ among 40 caregivers of patients with oral cancer found an association of age with caregiver burden highly significant but the association of type of family and marital status was not found significant. Findings were consistent with this study (Table 1).

Despite contributing the high in numbers caregiving burden was felt least among housewives (69\%). While the contrast was seen among professionals contributing least in numbers for caregiving had experienced a lot of Caregiving burden (61.5\% but the burden was not statistically significant. In contrast, Hiremath P et al. ${ }^{14}$ reported that the occupation of the caregiver was significantly associated with caregiver burden. The difference might be due to studies conducted at different regions or inclusion of caregivers of a specific type/all type of cancer patients. Lixia and Mordiffi et al. ${ }^{13}$ done a systematic review to examine the associated factors of higher caregiver burden among family caregivers of elderly cancer patients reported higher caregiver burden among employed. The maximum caregiving burden observed in the middle class. The association of socioeconomic status with caregiver burden was found statistically significant in the present study. It might be due to those caregivers who belonged to the middle class are in the mid of socioeconomic strata. Due to caregiving to the cancer patient, they are more affected financially as well as psychologically as compared to the lower class people who are affected less psychologically or to the upper-class people who are affected less financially. Similar to findings of this study, Salmani $\mathrm{N}$ et al. ${ }^{15}$ in their study conducted among 60 caregivers of the patients hospitalized in oncology of Shah Vali Hospital of Yazd city reported that direct relationship of caregiver burden was found with socioeconomic status (Table 2).

Table 1: Association of socio-demographic factors with caregiver burden among caregivers of cancer patients

\begin{tabular}{|c|c|c|c|}
\hline \multirow[t]{2}{*}{ Variable } & \multicolumn{2}{|c|}{ Caregiver burden } & \multirow[t]{2}{*}{ Total $(\mathrm{N}=\mathbf{3 4 0})$} \\
\hline & Present $n=246(74.6 \%)$ & $\begin{array}{c}\text { Absent n=94 } \\
(27.6 \%)\end{array}$ & \\
\hline \multicolumn{4}{|l|}{ Age } \\
\hline $18-29$ & $19(70.4 \%)$ & $8(29.6 \%)$ & $27(8.00)$ \\
\hline $30-44$ & $122(82.4 \%)$ & $26(17.6 \%)$ & $148(43.50)$ \\
\hline $45-59$ & $95(64.2 \%)$ & $53(35.8 \%)$ & $148(43 \cdot 50)$ \\
\hline 60 and above & $10(58.8 \%)$ & $7(41.2 \%)$ & $17(5.00)$ \\
\hline \multicolumn{4}{|c|}{$\chi^{2}$ value $=14.06 ; \mathrm{Df}=3 ; \mathrm{p}$ value $=0.002$} \\
\hline \multicolumn{4}{|c|}{ Sex } \\
\hline Male & $168(81.1 \%)$ & $39(18.9 \%)$ & $197(57.90)$ \\
\hline
\end{tabular}


Table 1: (Continued)

\begin{tabular}{|c|c|c|c|}
\hline \multirow[t]{2}{*}{ Variable } & \multicolumn{2}{|c|}{ Caregiver burden } & \multirow[t]{2}{*}{ Total $(\mathrm{N}=340)$} \\
\hline & Present $n=246(74.6 \%)$ & $\begin{array}{c}\text { Absent } \mathrm{n}=94 \\
(27.6 \%)\end{array}$ & \\
\hline \multirow[t]{2}{*}{ Female } & $78(58.6 \%)$ & $55(41.4 \%)$ & $143(42.10)$ \\
\hline & $36-4.96) ; \chi^{2}$ value $=20.46$ & $\mathrm{e}=<0.001$ & \\
\hline \multicolumn{4}{|c|}{ Area of Residence } \\
\hline Rural & $132(65 \cdot 3 \%)$ & $70(34 \cdot 7 \%)$ & $202(59.40)$ \\
\hline Urban & $114(82.7 \%)$ & $24(17 \cdot 3 \%)$ & $138(40.60)$ \\
\hline \multicolumn{4}{|c|}{ OR=0.397:Pvalue=0.00048 $(<0.001)$} \\
\hline \multicolumn{4}{|c|}{ Marital status } \\
\hline Married & $211(71.8 \%)$ & $83(28.2 \%)$ & $294(86.50)$ \\
\hline Unmarried & $17(77 \cdot 3 \%)$ & $5(22.7 \%)$ & $22(6.50)$ \\
\hline Widow & $18(75 \%)$ & $6(25 \%)$ & $24(7.00)$ \\
\hline \multicolumn{4}{|c|}{$\chi^{2}$ value $=0.4004 ; \mathrm{Df}=2 ; \mathrm{p}$ value $=0.818$} \\
\hline \multicolumn{4}{|c|}{ Type of family } \\
\hline Nuclear & $99(71.7 \%)$ & $39(28.3 \%)$ & $138(40.60)$ \\
\hline Joint & $147(72.8 \%)$ & $55(27.2 \%)$ & $202(59 \cdot 40)$ \\
\hline \multicolumn{4}{|c|}{$\mathrm{OR}=0.949(0.586-1.539) ; \chi^{2}$ value $=0.0436 ; \mathrm{Df}=1 ; \mathrm{p}$ value $=0.834$} \\
\hline \multicolumn{4}{|c|}{ Co-morbid physical illness } \\
\hline Present & $102(80.9 \%)$ & $24(19.1 \%)$ & $126(37-05 \%)$ \\
\hline Absent & $144(67 \cdot 3 \%)$ & $70(32.7 \%)$ & $214(62.95 \%)$ \\
\hline
\end{tabular}

$\mathrm{OR}=2.066(1.218-3.504) ; \chi 2$ value $=7.379 ; \mathrm{Df}=1 ; \mathrm{p}$ value $=0.006$

Table 2: Association of socio-demographic factors with caregiver burden among caregivers of cancer patients

\begin{tabular}{|c|c|c|c|}
\hline \multirow[t]{2}{*}{ Socioeconomic status } & \multicolumn{2}{|c|}{ Caregiver burden } & \multirow[t]{2}{*}{ Total (\%) } \\
\hline & Present & Absent & \\
\hline Upper Class & 16(76.2\%) & $5(23.8 \%)$ & $21(6.2)$ \\
\hline Upper Middle Class & $39(75 \%)$ & $13(25 \%)$ & $52(15 \cdot 3)$ \\
\hline Middle Class & $76(86.4 \%)$ & $12(13.6 \%)$ & $88(25.9)$ \\
\hline Lower Middle Class & $60(64.5 \%)$ & $33(35 \cdot 5 \%)$ & $93(27 \cdot 3)$ \\
\hline Lower Class & $55(63.9 \%)$ & $31(36.1 \%)$ & $86(25 \cdot 3)$ \\
\hline \multicolumn{4}{|c|}{$\chi^{2}$ value $=14.86 ; \mathrm{Df}=4 ; \mathrm{p}$ value $=0.0049$} \\
\hline \multicolumn{4}{|c|}{ Education } \\
\hline Illiterate & $32(65 \cdot 3 \%)$ & $17(34 \cdot 7 \%)$ & $49(14.4)$ \\
\hline Up to middle school & $108(70.6 \%)$ & $45(29.4 \%)$ & $153(45.0)$ \\
\hline Above middle school & $106(76.8 \%)$ & $32(23.2 \%)$ & $138(40.6)$ \\
\hline \multicolumn{4}{|c|}{$\begin{array}{l}\chi 2 \text { value }=2.826 ; \mathrm{Df}=2 ; \mathrm{p} \text { value }=0.2434 \\
\text { Occupational status }\end{array}$} \\
\hline Professional/semiprofessional & $8(61.5 \%)$ & $5(38.5 \%)$ & $13(3.8)$ \\
\hline Shopkeeper/ Farmer & $51(68.9 \%)$ & $23(31.1 \%)$ & $74(21.7)$ \\
\hline Skilled/ Semi skilled & $67(83 \cdot 7 \%)$ & $13(16.3 \%)$ & $80(23.5)$ \\
\hline Unskilled & $38(67.8 \%)$ & $18(32.2 \%)$ & $56(16.5)$ \\
\hline Unemployed & $16(72.7 \%)$ & $6(27 \cdot 3 \%)$ & $22(6.5)$ \\
\hline Housewife & $49(69 \%)$ & $22(31 \%)$ & $71(20.9)$ \\
\hline Others & $17(70.8 \%)$ & $7(29.2 \%)$ & $24(7.1)$ \\
\hline
\end{tabular}

$\chi^{2}$ value $=7.382 ; \mathrm{Df}=6 ; \mathrm{p}$ value $=0.2870$ 


\section{CONCLUSION}

The present Study reflected caregiver burden amongst male and the younger age group, 30 to 45 were found to be significantly burdened. Despite contributing only less in numbers, urban caregivers experienced significantly high caregiver burden. As far marital status is concerned, unmarried caregivers were found to be more burdened as compared to other marital statuses. These finding suggested coping with the problem of care-giving burden more policies and programmes in this direction should have been planned with special attention particularly to reduce burden amongst those having more suffering.

\section{ACKNOWLEDGEMENT}

We would like to thank Dr PK Kasar Prof Dept community medicine for immense, help in every aspect of work, Dr Aftab Khan (Associate Professor, Department of Psychiatry, N.S.C.B. Medical College, Jabalpur) who helped me in refining my knowledge regarding psychological component of this study, Dr Luxmi Singodiya (Professor and Head, department of oncology and Superintendent, Cancer Hospital Jabalpur) who helped me in conducted this study in the hospital.

\section{Conflict of interest: Nil}

Source of funding: Nil

\section{REFERENCES}

1. State Health Systems Resource Centre National Rural Health Mission. Department of Health and Family Welfare, Punjab. 2012.

2. Garlo K, O'Leary JR, Van PH, Fried TR. The burden in caregivers of older adults with advanced illness. J Am Geriatr Soc 2010;58:2315-22.
3. Goldstein NE, Concato J, Fried TR, Kasl SV, Johnson-Hurzeler $\mathrm{R}$, Bradley EH. Factors associated with caregiver burden among caregivers of terminally ill patients with cancer. J Palliat Care 2004;20:38-43.

4. Savundranayagam MY, Montgomery RJ, Kosloski K. A dimensional analysis of caregiver burden among spouses and adult children. Gerontologist 2011;51:321-31.

5. Hebert RS, Arnold RM, Schulz R. Improving well-being in caregivers of terminally ill patients. Making the case for the patient suffering as a focus for intervention research. J Pain Symptom Mgmt 2007;34:539-4.

6. Chaturvedi SK. Psychiatric oncology: Cancer in mind. Indian J Psychiatry 2012;54:111-8.

7. Shankar A, Dracham C, Ghoshal S. Prevalence of depression and anxiety disorder in cancer patients: An institutional experience. Indian J Cancer 2016;53:432-4.

8. Kim Y, Schulz R. Family caregivers' strains: Comparative analysis of cancer caregiving with dementia, diabetes, and frail elderly caregiving. J Aging Health 2008;20:483-503.

9. Paulina A, Anarado AN. Perceptions of the burden of caregiving by informal caregivers of cancer patients attending the University of Calabar Teaching Hospital, Calabar, Nigeria. Pan African Med J 2014;18:159.

10. Australian Bureau of Statistics. Disability, aging, and carers, Australia: Summary of findings, 1998, Australian Bureau of Statistics. 1999.

11. Zarit SH, Reever KE, Bach PJ. Relatives of the impaired elderly: Correlates of feelings of burden. Gerontologist. 1980;20:649-55.

12. Lukhmana S, Bhasin SK, Chhabra P, Bhatia MS. Family caregivers' burden: A hospital-based study in 2010 among cancer patients from Delhi. Indian J Cancer 2015;52:146-51.

13. Lixia G, Mordiffi S. Factors Associated With Higher Caregiver Burden Among Family Caregivers of Elderly Cancer Patients: A Systematic Review. Cancer Nur 2017;40:471-8.

14. Hiremath P, Mohite VR, Naregal P, Chendake M, Mulani A, More UR. Family burden and stress among caregivers of oral cancer patients at Krishna hospital, Karad. Asian J Pharm Clin Res 2017;10:201-6.

15. Salmani N, Ashketorab T, Hasanvand S. The burden of caregiver and related factors of oncology. Adv Nursing Midwifery 2015; 24:305. 